\title{
FACTORS INFLUENCING PEER RELATIONSHIPS OF HEARING IMPAIRED CHILDREN
}

\author{
Xie Yuhan*
}

\begin{abstract}
Peer relationships of hearing impaired children is an important element for their social integration, it plays a critical role on their cognitive, emotional and behavioral development. But hearing impaired children have difficulties in interacting with peers, especially with hearing peers. In order to improve their peer relationships, first of all, influencing factors should be made clear. The present article provides an overview of factors affecting peer relationships of hearing impaired children. Summarizing available researches, there are main four affecting factors: educational settings, cochlear implants, communication strategies, and attachment. Each of factors is described, with attention to their relative negative and positive influences and how these factors impact on peer relationships of hearing impaired children is analyzed deeply. Furthermore, besides these factors, other influencing factors should be investigated in future.
\end{abstract}

\section{Key words}

Peer relationships, hearing impaired children, educational settings, cochlear implants, communication strategies, attachment

\section{Introduction}

Peer relationships refer to the interactions among age-mates (Hartup, 1986), which play an important role in children's emotional and social development. Hartup (1996) points out that peers affect children's development in two ways: one is participation in group activities; another is dyadic (i. e. one-on-one) associations with friends. Both facets make children experience different peer relationships, for example, being accepted or rejected by peers. Peer relationships provide children context for construction of the self, in

* Xie Yuhan, doctoral student, Institute of Special Education, Faculty of Education, Palacký University, Olomouc, Czech Republic; Lecture, Faculty of Education Science, Sichuan Normal University, China. 
which capacities for self-control may be tested and refined. And peer relationships also offer the age-related developmental opportunities for getting acquainted with social norms and processes, learning cooperation, gaining support, or developing interpersonal skills (Rubin et al., 1998). Positive interactions and relationships with peers are associated with greater psychological well-being at all ages (Ladd et al., 2005), more academically successful (Buhs et al., 2006), better school adjustment, successful emotion regulation, and maintaining positive peer relationships in the future. (Mcelwain \& Valling, 2005).

Spoken language and vocalization play a central role in social interactions. For children with hearing impairment, different degree hearing loss inevitably influences the development of their social behavior and emotion. Some researches suggest that many deaf children have difficulties in initiating interactions with hearing peers (Weisel et al., 2005), they are more likely to be neglected by peers (Nunes et al., 2001) and report more loneliness than do hearing children (Most, 2007).Based on these researches, it might be deduced that hearing impaired children may face increasing difficulties in forming and sustaining positive relationships with hearing peers.

Besides hearing loss and poor ability of oral language, what are the impacting factors on the peer relationships of hearing impaired children? In order to improve the peer relationships of hearing impaired children, the influencing factors should be made clear. The goal of the present article is to provide an overview of factors influencing the peer relationships of children with hearing impairment. On the base of relevant literatures in this area, main four factors are summarized: educational setting, cochlear implants, communication strategies, and attachment.

\section{Educational settings}

The educational setting is very crucial to the development of social competence (i. e., peer relationships) of children with hearing impairment. Children who are deaf have multiple school placement options: residential deaf schools, day deaf schools, or mainstreaming in hearing schools, either fully or partially. Nowadays, in many countries, inclusion of children with disabilities, including deaf children, is a core element of educational policy. If possible, deaf children are educated in mainstream settings. 
Many researches indicate that mainstream settings are better for academic achievement of children with hearing impairment. Deaf students in the mainstream setting have higher levels of achievement than those in segregated settings. (Jensema, 1975; Reich et al., 1977), but their social integration is not as evident. More and more researchers focus on the social integration of hearing impaired children, they report that deaf students in the mainstream tend to have lower self esteem, to be socially isolated and to feel lonely, and to be less well adjusted than those in segregated settings (Charlson et al., 1992). It appears that deaf children in mainstream education often have few friends, have less interaction with hearing peers, and are more often rejected or neglected than their hearing peers. (Kluwin et al., 2002; Musselman et al., 1996; Stinson \& Antia, 1999; Stinson \& Kluwin, 2003). Nunes et al. (2001) investigated the social adaptation of deaf pupils in mainstream schools. The results show that deaf pupils were significantly more likely to be neglected by their peers and less likely to have a friend in the classroom than hearing pupils. Although deaf pupils are not rejected in mainstream schools, but they may feel isolated. And deaf adults who educated in special schools reported more positive memory than those educated at mainstream schools (Mertens, 1989). Pupils with hearing impairment who experienced both types of school environment often report a strong preference for special schools (Gregory et al., 1995). There is evidence that special programming can improve the relationships between deaf and hearing students (Kluwin \& Gonsher, 1994; Ladd et al., 1984). Thus, although not all results are equally negative, the preponderance of the evidence supports the conclusion that special schools for the deaf foster socio-emotional growth better than mainstream schools.

However, some researches show that social integration seems somewhat more positive for hearing impaired children in a co-enrollment program in inclusive setting. Co-enrollment program is one model of inclusive education for students with hearing losses, in which hearing impaired students and hearing students learn together in a classroom, which is co-taught by a regular education teacher and a special education teacher for hearing impaired students. Co-enrollment programs provide the opportunity for intensive contact between hearing impaired children and their hearing peers (Antia \& Kreimeyer, 2003; Kirchner, 1994). A study examined the social and academic performance of the deaf/hard -of-hearing children in the co-enrollment program. Results showed that co-enrollment intervention in inclusive setting promoted 
students' academic development and increased interaction between $\mathrm{D} / \mathrm{HH}$ children and hearing peers (Kreimeyer et al., 2000). A research by Wauters $\&$ Knoors (2007) investigates the social integration of hearing impaired children in both co-enrollment and mainstream programs by focusing on peer acceptance, social competence, and friendship relations. The results suggest that no differences are found between the deaf children and their hearing peers in peer acceptance, social status, the number of mutual friendships, and the number of mutual antipathies. It demonstrates that peer relationships of hearing impaired children can be benefited from inclusive settings.

From the studies available, it seems that the effects of educational settings on peer relationships of hearing impaired children are inconclusive. Some researchers observe that mainstream setting is good for social integration of hearing impaired children (Wauters \& Knoors, 2007), but others have opposite views (Nunes et al., 2001). Therefore, more studies about this issue should be needed in the future.

\section{Cochlear implants}

Since the mid-1980s, the cochlear implants have been used for children who have a profound hearing loss, which marked a major breakthrough in the rehabilitation of deaf children. Unlike traditional hearing aids that amplify sounds, cochlear implants provide hearing-like sensation by directly stimulating the auditory nerve, contribute to restore auditory in formation to deaf children and improve the ability of speech recognition. The criteria of cochlear implantation have relaxed, such as lower age at implant, lower levels of hearing loss; and the cochlear implants' technology have made great improvement. Thus, the number of deaf children who received cochlear implants has increased dramatically.

The difficulties that deaf children typically experience in socialization with hearing peers may be attributed to limited production of intelligible speech and speech comprehension, resulting in inadequate understanding of how others think and feel (Remmel \& Peters, 2009; Schorr et al., 2009). So, hearing loss leads to obstacles for hearing impaired children when they are communicating with hearing peers. In theory, if cochlear implants could improve auditory perception and advance speech and oral language skills in young deaf children, it could contribute to a common system of communication between the deaf child and his or her hearing parents and peers, promoting skills necessary for positive peer relationships. 
Some studies have investigated peer relationships of children with cochlear implants, and indicate that the cochlear implants can markedly improve the communication skills of deaf children and have a positive effect on deaf children's ability to socialize with hearing peers in a mainstream environment (Pisoni et al., 1999; Svirsky et al., 2000; Tomblin et al., 1999). Cochlear implants may aid in the early socio-emotional development of some deaf children (Susan et al., 2010). A research assessed the conversational skills of children with cochlear implants, the results show that they talk as much and contribute to solving the task as efficiently as their hearing peers (Ibertsson, 2009). The research by Bat-Chava et al. (2005) concludes that deaf children with cochlear implants or hearing aids, whose communication skills improve overtime, this performance improves faster in children with implants compared to children with hearing aids. It demonstrates that cochlear implants may be effective in improving deaf children's communication and social skills, resulting in more satisfying interactions with hearing peers. Bat-Chava \& Deignan (2001), using a qualitative and quantitative analysis of interviews with parents, described deaf children's communication skills and peer relationships before they had the implant and afterward. Results reveal that the implant has the potential to improve deaf children's relationships with hearing peers.

However, some researches don not conclude so positive results. A research shows that younger children with cochlear implants (aged 5-9 years) experience the same levels of loneliness and peer acceptance as normally hearing children; older children with cochlear implants (aged 9-14 years) report significantly lower perception of their own appropriate conduct and marginally greater loneliness than normally hearing children. In addition, the perception of loneliness is greater for children who received implants later in life (Schorr, 2006). In a study 5-to 6-year old deaf children who had cochlear implants for at least 1 year were observed under conditions varying peer context difficulty in A Peer Entry Task. Results suggested that they had no difficulty socializing with hearing peers in one-on-one situations, but still have difficultly when faced with an already established dyad of unfamiliar hearing peers (Martin D. et al., 2010). Researches investigate social skills of deaf children with cochlear implants using the peer entry paradigm, which indicate that one third of children with implants failed to enter a group situation where a dyad of hearing peers was already interacting (Knutson et al., 
1997); $27 \%$ deaf children with implants failed to enter a peer group of two hearing peers compared to $5 \%$ of hearing children who failed entry (Boyd et al., 2000). These results suggest that deaf children with cochlear implants demonstrate on going communication limitations.

A growing literature demonstrates the positive effects of cochlear implants on auditory perception and speech and oral language development (Hayes et al., 2009; Waltzman, 2006). Based on the view, cochlear implants have positive effects on deaf children's social skills and peer relationships, through improving auditory perception and speech and oral language development, why some studies do not show such positive results? Because cochlear implants don not have effects on auditory perception and speech and oral language development directly, these benefits are moderated by several variables, such as age at implant, duration of implant use, and mode of communication. Early profound hearing loss, later age at implantation is related to poorer speech perception (Zwolan et al., 2004) and speech production (Geers et al., 2009; Robbins, 2006), likely due to age-dependent aural sensitivity (Connor, et al., 2006). Longer duration of cochlear implant use is associated with better oral language (Nicholas \& Geers, 2006), better performance on the communication with peers (Martin et al., 2010). There seems to be a substantial benefit for both speech and vocabulary outcomes when children receive their implant before the age of 2.5 years old. This benefit may combine a burst of growth after implantation with the impact of increased length of use at any given age. The added advantage (i. e., burst of growth) diminishes systematically with increasing age at implantation (Connor et al., 2006). The benefits of cochlear implantation both in the areas of communication and socialization while pointing to the interactive nature of these factors in children's development (Bat-Chava et al., 2005; Schorr et al., 2009).

\section{Communication strategies}

As age growing, the social skills of children develop, their participation in social interactions becomes more and more intentional (Eckerman \& Stein, 1982). As children gradually take on more responsibility for social interactions with peers, they need to develop various communication skills further, such as the ability to initiate social interactions successfully (Ghuman et al., 1998). There are many different communication strategies, strategies to initiate interactions used by children is one of most important communication 
strategies, which begin during early childhood and can be seen in kindergartens (Erwin et al., 1999).

What is initiation strategy in interaction? Vandell \& George (1981) express the view that any clear and distinct behavior toward a partner that is not a part of an already existing interaction can be considered as an initiation strategy. An initiation strategy is successful when the partner responds and an interaction occurs. For hearing children, spoken language and vocalization play a central role in social interactions; both are used as strategies for initiating an interaction and for maintaining its continuity (Lederberg et al., 1986). But for hearing impaired children, who have great problem with development of spoken language, may have a lot of difficulties in social interactions.

The initiation strategies used by hearing impaired children are different from ones used by hearing children. Higginbotham and Baker (1981) reported that hearing impaired kindergartners spent more time playing alone in comparison to same-age hearing children. Duncan (1999) concluded that the deaf kindergartners used more physical initiation strategies (i. e., touch) than did their hearing counterparts in integrated kindergartens. Weisel et al. (2005) reported that initiation strategies used mainly by hearing impaired children as follows: vocalization, which only is preverbal vocalization such as single vowels, single syllable, and repeated syllables, either as a simple strategy or in combination with other strategies comprised the most frequent means of initiating peer interactions. Other strategies are touch, signing, object-related social act, head turning, moving closer, imitation of play, and direct entrance.

With reference to the effect of these initiation strategies, the hearing impaired children made more attempts to initiate social interaction with hearing peers than with their deaf peers, but initiations toward the deaf children were more successful than those toward the hearing children (Vandell \& George, 1981). It concluded that even when hearing and HI children used similar strategies, the $\mathrm{HI}$ initiators failed more often, especially when attempting to initiate interactions with hearing peers. Be inline with this view, Weisel et al. (2005) reported that success rates of initiation strategies used by HI children in the special program were much higher than the rates in the regular program. In the special program, HI children communicate with only with other deaf children; in the regular program, HI children communicate with not only deaf children but also hearing children. Researchers interpreted that perhaps the specific strategy that hearing impaired children used did not 
comprise the main determinant of their success. For example, the vocalizations made by the HI children included mostly preverbal vocalizations, which was not suitable for hearing partners and could not be understood by their partners, especially in the regular program. Thus, it might be that the low rate of success was related to the quality of these vocalizations. The other reason is that although HI children's motivation of the participants to interact with the hearing children is very strong and clear, they continued to repeat their attempted social interactions despite repeated failures (Weisel et al., 2005).

Moreover, trouble in communication between deaf and hearing children was related not only to different abilities to either understand the other's language, but to interaction or sociolinguistic practices specific to each modality (Keationg \& Mirus, 2003). Some studies found that HI preschoolers did not change their initiation strategies to accommodate hearing or deaf partners (Rodriguez \& Lana, 1996). And hearing preschoolers used only vocalizations when they interacted with hearing partners and did not change their initiations to meet the HI children's needs (Vandelland \& George, 1981). Thus, these reasons lead to relatively higher number of initiations made by HI children, but lower rate of success in the regular program. Keationg \& Mirus (2003) point out that unshared sociolinguistic practices and hearing-oriented participation frameworks are crucial aspects of communicative failure between hearing and deaf children in mainstream elementary school settings. And they suggest that deaf children are expected to develop skills for accommodating to hearing children, hearing children in classes with deaf children should be expected to develop comparable skills for interacting with deaf students in order to enrich peer interactions and enable the deaf students to have equal access to all learning opportunities.

\section{Attachment}

Attachment is a special emotional bonding between the infant and caregiver who mainly is mother (Bowlby, 1969). From the moment when a baby is born, he or she innate repertoire of behaviors such as smiling and the grasping reflex help them bond with their mothers and the attachment is forming through the interactions between mother and child. Attachment is considered as internal working models that serve later in the establishment of new relationships, it is very necessary and important for the development and establishment of satisfying interpersonal relationships (Bowlby, 1988; Marcel $\&$ Broesterhuizen, 2001). Secure attached children whose needs have been 
met in a socially responsive environment have better ability to explore the environment and are more likely to be more socially competent. They have more satisfying relationships with friends, particularly with spouses (Blatt \& Blass, 1990), better vocational and professional adjustment (Bartholomew $\&$ Horowitz, 1991), better ability to cope with stressful situations and negative affects (Mikulincer et al., 2003; Mikulincer et al., 2003; Pereg \& Mikulincer, 2004), better self-image (Mikulincer, 1995), and a stronger sense of well-being (Diehl et al., 1998; Grotevant \& Cooper, 1998; Hazan \& Shaver, 1990). On other hand, those children who developed insecure attachment have shown fear in unfamiliar situations and would become extremely nervous, becoming depressed and withdrawn, distrust, anger, aggressiveness, and insensibility (Page \& Bretheron, 2001).

The presence of a child with a disabling condition, such as a hearing impaired child, has a significant impact on the family, may alter the family communication patterns, its interpersonal relationships, and family climate, especially when the parents are hearing, thus affecting the attachment as well (Weisel \& Kamara, 2005; Christiansen \& Leigh, 2002). Hearing impaired children are assumed to be at risk for developing an insecure attachment, especially deaf children with hearing mothers. There may be several reasons. First, when the child's hearing deficit is diagnosed, hearing mother often reveal stress and depression, then might neglect or be insensitive to the needs, initiations, or wishes of the young baby. Second, hearing mother may fail to adjust the communication to child, still continuing to comfort the child by voice, but child with hearing impairment cannot hear the mother's voice. Third, the child with hearing impairment cannot hear the mother when she is not visible and therefore does not have the continued assurance about her presence or the comfort that the mother's voice can provide, which in hearing children can reduce separation anxiety. Furthermore, a hearing impaired child may do not know his or her own voice is important in communication and fail to influence caretakers' behavior or attention (Lederberg \& Prezbindowski, 2000; Meadow-Orlans, 1997). Greenberg \& Marvin (1979) investigated the impact of attachment patterns on deaf preschool children's competence; they found that the children's level of communicative competence was shown to be associated with qualitatively different patterns of attachment. Children with more secure representations of attachment and less avoidant responses showed more socially cooperative interactions and greater independent than those with more insecure representations if attachment 
and more avoidant responses(Kim \& Kim, 2008). In a research by Marcel $\&$ Broesterhuizen (2001), deaf students at the age between three and seven years were investigated. The results indicate that there is a clear relationship between secure attachment and the parents and socio-metric status. Students who are secure attached report that they have no feelings of alienation toward their parents; they are popular and well accepted by their peers. Researchers explained that adolescents have an "internal working model" of their relationship with parents that continue to be determinate their attitude towards others and towards themselves. Deaf children with secure attachment trust their parents and others, so they are likely to learn social behaviors leading to be accepted by peers and are easier to get friendship with peers. (Marcel \& Broesterhuizen, 2001).

Although available researches on attachment and peer relationships of hearing impaired children published are so limited, it is not doubtful that attachment of hearing impaired children plays an important role on their peer relationships. In future, research in this field should be explored deeply.

\section{Conclusion}

Peer relationships of hearing impaired children is an important element for their social integration, it plays a critical role in their cognitive, emotional and behavioral development. Many researches demonstrate that hearing impaired children face lots of difficulties in interaction with peers, especially with hearing peers in inclusive setting. Improving their peer relationships becomes an urgent task for special education for hearing impaired children, in order to facilitate their social competence and mental heath. First of all, influencing factors on peer relationships of hearing impaired children should be made clear. Reviewing available studies in this field, it found that there are important four factors: educational settings, cochlear implants, communication strategies, and attachment. Besides these factors, more other influencing factors such as the theory of mind, personality, parenting styles and so on should be investigated in future. Furthermore, various factors provide different perspectives on hearing impaired children's peer relationships and sociability. But these factors impact on peer relationships not separately, but interactively. So, a combination of perspectives will provide the fullest picture of hearing impaired children's peer relationships and directions for understanding and supporting positive peer relationships. 


\section{References}

ANTIA, S. D., \& KREINMEYER, K. H. (2003). Peer Interactions of Deaf and Hard-of-hearing Children. In M. Marschark \& M. E. Spencer (Eds.), Deaf Studies, Language, and Education. New York: Oxford University Press, 164-176.

BARTHOLOMEW, K. \& HOROWITZ, L. M. (1991). Attachment Styles Among Young Adults: A Test of a Four-category Model. Journal of Personality and Social Psychology, 61 (2), 226-244.

BAT-CHAVA, Y., \& DEIGNAN, E. (2001). Peer Relationships of Children with Cochlear Implants. Journal of Deaf Studies and Deaf Education, 6(3), 186-199.

BAT-CHAVA, Y., MARTIN, D., \& KOSCIW, J. G. (2005). Longitudinal Improvements in Communication and Socialization of Deaf Children with Cochlear Implants and Hearing Aids: Evidence from Parental Reports. Journal of Child Psychology and Psychiatry, 46(12), 1287-1296.

BLATT, S. J., \& BLASS, R. B. (1990). Attachment and Separateness: A Dialectic Model of the Products and Processes of Development Throughout the Life Cycle. The Psychoanalytic Study of the Child, 45, 107-127.

BOWLBY, J. (1969). Attachment and Loss (Vol. 1). London: The Hogarth Press and the Institute of Psycho-Analysis. The International Psycho-Analytical Library, 79: 1-401.

BOWLBY, J. (1988). A Secure Base: Clinical Applications of Attachment Theory. London: Routledge. This article is found on the website: http://www.richardatkins.co.uk/atws/document/12.html

BOYD, R. C., KNUTSON, J. F., \& DAHLSTROM, A. (2000). Social Interaction of Pediatric Cochlear Implant Recipients with Age-matched Peers. The Annals of Otology, Rhinology, and Laryngology, 185 (Supp 1.), 105-109.

BROESTERHUIZEN, M. (2001). Development of Friendship and Prosociality in Deaf Children, pp. 87-99. This article is found on the website: http://www.google.com.hk/search.

BUHS, E. S., LADD, G. W., \& HERALD, S. L. (2006). Peer Exclusion and Victimization: Processes That Mediate the Relation Between Peer Group Rejection and Children's Classroom Engagement and Achievement? Journal of Educational Psychology, 98(1), 1-13.

CHARLSON, E., STRONG, M., \& GOLD, R. (1992). How Successful Deaf Teenagers Experience and Cope with Isolation. American Annals of the Deaf, 7(3), 261-270. 
CHRISTIANSEN, J. B., \& LEIGH, I. W. (2002). Cochlear Implants in Children: Ethics and Choices. Washington, DC: Gallaudet University Press, 290-300.

CONNOR, C. M., CRAIG, H. K., RAUDENBUSH, S. W., HEAVNER, K. \& ZWOLAN, T. A. (2006). The Age at Which Young Deaf Children Receive Cochlear Implants: Is There an Added Value for Early Implantation? Ear and Hearing, 27(6), 628-644.

DIEHL, M., ELNICK, A. B., BOURBEAU, L. S., \& LABOUVIE-VEIF, G. (1998). Adult Attachment Styles: Their Relations to Family Context and Personality. Journal of Personality and Social Psychology, 74 (6), 1656-1669.

DUNCAN, J. (1999). Conversational Skills of Children with Hearing Loss and Children with Normal Hearing in Integrated Setting. The Volta Review, 101(4), 193-211.

ECKERMAN, C. O., \& STEIN, M. R. (1982). The Toddler's Emerging Interactive Skills. In K. H. Rubin \& H. S. Ross (Eds.), Peer Relationships and Social Skills in Childhood. New York: Springer-Verlag, 41-71.

ERWIN, E. J., ALIMARAS, E.,\& PRICE, N.(1999). A Qualitative Study of Social Dynamics in an Inclusive Preschool. Journal of Research in Childhood Education, 14(1), 56-67.

GEERS, A. E., MOOG, J. S., BIEDENSTEIN, J., BRENNER, C., \& HAYES, H. (2009). Spoken Language Scores of Children Using Cochlear Implants Compared to Hearing Age-mates at School Entry. Journal of Deaf Studies and Deaf Education, 14(3), 371-385.

GHUMAN, J. K., PEEBLES, C. D., \& GHUMAN, H. S. (1998). Review of Social Interaction Measures in Infants and Preschool Children. Infants and Young Children, 11(2), 21-44.

GROTEVANT, H. D., \& COOPER, C. R. (1998). Individuality and Connectedness in Adolescent Development. In E. Skoe, \& A. V. Lippe (Eds.), Personality Development in Adolescence. London: Routledge, 3-37.

GREENBERG, M. T., \& MARVIN, R. (1979). Attachment Patterns in Profoundly Deaf Preschool Children. Merrill-Palmer Quarterly, 25 (4), 265-279.

GREGORY, S., BISHOP, J., \& SHELDON, L. (1995). Deaf Young People and Their Families. Cambridge (UK): Cambridge University Press, 154-180. 
HARTUP, W. W. (1986). On Relations and Development. In W. W. Hartup, $\&$ Z. Rubin (Eds.), Relationships and 'Development. Hillsdale, NJ: Lawrence Erlbaum, 1-26.

HARTUP, W. W. (1996). The Company They Keep: Friendships and Their Developmental Significance. Child Development, 67(1), 1-13.

HAYES, H., GEERS, A. E., TREIMAN, R., \& MOOG, J. S. (2009). Receptive Vocabulary Development in Deaf Children with Cochlear Implants: Achievement in an Intensive Auditory Oral Educational Setting. Ear and Hearing, 30(1), 128-135.

HAZAN, C., \& SHAVER, P. (1990). Love and Work: An Attachment Theoretical Perspective. Journal of Personality and Social Psychology, 59(2), 270-280.

HIGGINBOTHAM, D. J., \& BAKER, B. M. (1981). Social Participation and Cognitive Play Differentces in Hearing-impaired and Normally Hearing Preschoolers. Volta Review, 83(3), 135-149.

IBERTSSON, T. (2009). Cognition and Communication in Children/Adolescents with Cochlear Implant. Printed by Media-Tryck, Lund University, Lund, Sweden. Lund University, Faculty of Medicine Doctoral Dissertation Series 2009:95.

JENSEMA, C (1975). The Relationship Between Academic Achievement and the Demographic Characteristics of Hearing Impaired Children and Youth. (Series R, No. 2.) Office of Demographic Studies. Washington, DC: Gallaudet College, 2-18.

KEATIN, E., \& MINRUS, G. (2003). Examining Interactions across Language Modalities: Deaf Children and Hearing Peers at School. Anthropology and Education Quarterly, 34(2), 115-135.

KLUWIN, T. N., \& GONSHER, W. (1994). A Single School Study of Social Integration of Children with and without Hearing Losses in a Team Taught Kindergarten. ACEHI/ACEDA Journal, 20(3), 74-87.

KLUWIN, T. N., STINSON, M. S., \& COLAROSSI, G. M. (2002). Social Processes and Outcomes of In-school Contact Between Deaf and Hearing Peers. Journal of Deaf Studies and Deaf Education, 7(3), 200-213.

KIM, H. H., \& KIM, S. R. (2008). The Relationship Between Preschool Children's Representation of Attachment and Their Relationship to Teachers, Social Skills, and Behavior Problems. Journal of Research in Early Childhood Education, 2(1), 169-184. 
KIRCHNER, C. J. (1994). Co-enrollment as an Inclusion Model. American Annals of the Deaf, 139(2), 163-164.

KNUTSON, J. F., BOYD, R. C., REID, J. B., MAYNE, T., \& FETROW, R. (1997). Observational Assessments of the Interaction of Implant Recipients with Family and Peers: Preliminary Fndings. Otolaryngology-Head and Neck Surgery, 117(3), 196-207.

KREIMEYER, K. H., CROOKER, P., DRYE, C., EGBERT, V., KLEIN, B. (2000). Academic and Social Benefits of a Co-enrollment Model of Inclusive Education for Deaf and Hard-of-hearing Children. Journal of Deaf Studies and Deaf Education, 5(2), 174-185.

LADD, G. W., HERALD, S. L., ANDREWS, R. K. (2005). Children's Peer Relations and Social Competence: A Century of Progress. In B. Spodek, $\&$ O. N. Saracho (Eds.), Handbook of Research on the Education of Young Children (2nd ed.). Mahwah, NJ: Lawrence Erlbaum Associates, 23-54.

LADD, G. W., MUNSON, J. L., \& MILLER, J. K. (1984). Social Integration of Deaf Adolescents in Secondary Level Mainstreaming Programs. Exceptional Children, 50(5), 420-429.

LEDERBERG, A. R., RYAN, H. B., \& ROBBINS, B. L. (1986). Peer Interaction in Young Deaf Children: The Effect of Partner Hearing Status and Familiarity. Developmental Psychology, 22(5), 691-700.

LEDERBERG, A. R., \& PREZBINDOWSKI, A. K. (2000). Impact of Child Deafness on Mother-Toddler Interaction: Strengths and Weaknesses. In P. E. Spencer, C. J. Erting, \& M. Marschark, (Eds.), The Deaf Child in the Family and at School. Mahwah, NJ: Lawrence Erlbaum, 73-92.

MARTIN, D., BAT-CHAVA, Y., LALWANI, A., WALTZMAN, S. B. (2010). Peer Relationships of Deaf Children With Cochlear Implants: Predictors of Peer Entry and Peer Interaction Success. Journal of Deaf Studies and Deaf Education, 16(1), 108-120.

MCELWAIN, N. L., \& VOLLING, B. L. (2005). Preschool Children's Interactions with Friends and Older Siblings: Relationship Specificity and Joint Contributions to Problem Behavior. Journal of Family Psychology, 19(4), 486-496.

MEADOW-ORLANS, K. P. (1997). Effects of Mother and Infant Hearing Status on Interactions at Twelve and Eighteen Months. Journal of Deaf Studies and Deaf Education, 2(1), 27-36. 
MERTENS, D. M. (1989). Social Experiences of Hearing-impaired High School Youth. American Annals of the Deaf, 134(1) 15-19.

MIKULINCER, M. (1995). Attachment Style and the Mental Representation of the Self. Journal of Personality and Social Psychology, 69(6), 1203-1215. MINKULINCER, M., FLORIAN, V., \& HIRSCHBERGER, G. (2003). The Existential Function of Close Relationships: Introducing Death into the Science of Love. Personality and Social Psychology Review, 7(1), 20-40.

MIKULINCER, M., SHAVER, P. R., PEREG, D. (2003). Attachment Theory and Affect Regulation: The Dynamics, Development, and Cognitive Consequences of Attachment-related Strategies. Motivation and Emotion, 27(2), 77-102.

MOST, T. (2007). Speech Intelligibility, Loneliness, and Sense of Coherence among Deaf and Hard-of-hearing Children in Individual Inclusion and Group Inclusion. Journal of Deaf Studies and Deaf Education, 12(4), 495-503.

MUSSELMAN, C., MOOTILAL, A., \& MACKAY, S. (1996). The Social Adjustment of Deaf Adolescents in Segregated, Partially Integrated, and Mainstreamed Settings. Journal of Deaf Studies and Deaf Education, 1(1), 52-63.

NICHOLAS, J. G., \& GEERS, A. E. (2006). Effects of Early Auditory Experience on the Spoken Language of Deaf Children at 3 Years of Age. Ear and Hearing, 27(3), 286-298.

NUNES, T., PRETZLIK, U., \& OLSON, J. (2001). Deaf Children's Social Relationships in Mainstream Schools. Deafness and Education International, 3(3), 123-136.

PAGE, T. F., \& BRETHERTON, I. (2001). Mother-and Father-Child Attachment Themes in the Story Completion of Preschoolers from Post-divorce Families: Do They Predict Relationships with Peers and Teachers? Attachment and Human Development, 3(1): 1-29

PEREG, D., \& MIKULINCER, M. (2004). Attachment Style and the Regulation of Negative Affect: Exploring Individual Differences in Mood Congruency Effects on Memory and Judgment. Personality and Social Psychology Bulletin, 30 (1), 67-80.

PISONI, D. B., CLEARY, M., GEERS, A. E., \& TOBEY, E. A. (1999). Individual Differences in Effectiveness of Cochlear Implants in Children 
Who Are Prelingually Deaf: New Processes of Performance. The Volta Review, 101(3), 111-164.

REICH, C., HAMBLETON, D., \& HOULDIN, R. K. (1977). The Integration of Hearing-impaired Children in Regular Classrooms. American Annals of the Deaf, 122(6), 534-543.

REMMEL, E., \& PETERS, K. (2009). Theory of Mind and Language in Children with Cochlear Implants. Journal of Deaf Studies and Deaf Education, 14(2), 218-237.

ROBBINS, A. M. (2006). Language Development in Children with Cochlear Implants. In S. B. Waltzman \& J. T. Rolland (Eds.), Cochlear Implants (2nd ed.). New York: Thieme Medical, 153-166.

RODRIGUEZ, M.S., \& LANA, E. T. (1996). Dyadic Interactions Between Deaf Children and Their Communication Partners. American Annals of the Deaf, 141(3), 245-251.

RUBIN, K. H., BUKOWSKI, W., PARKER, J. G. (1998). Peer Interactions, Relationships, and Groups. In: N. Eisenberg (Ed.). Social, Emotional, and Personality Development. New York, NY: J. Wiley: 619-700.

SCHORR, E. (2006). Early Cochlear Implant Experience and Emotional Functioning During Childhood: Loneliness in Middle and Late Childhood. The Volta Review, 106(3), 365-379.

SCHORR, E., ROTH, F. P., \& FOX, N. A. (2009). Quality of Life for Children with Cochlear Implants: Perceived Benefits and Problems and the Perception of Single Words and Emotional Sounds. Journal of Speech, Language, and Hearing Research, 52, 141-152.

STINSON, M. S., \& ANTIA, S. D. (1999). Considerations in Educating Deaf and Hard-of-hearing Students in Inclusive Settings. Journal of Deaf Studies and Deaf Education, 4(3), 163-175.

STINSON, M. S., \& KLUWIN, T. N. (2003). Educational Consequences of Alternative School Placements. In M. Marschark \& M. E. Spencer (Eds.), Deaf Studies, Language, and Education.. New York: Oxford University Press, 52-64.

SUSAN, L., TASKER, MATILDA, E., NOWAKOWSKI, LOUSIS, A., SCHMIDT. (2010). Joint Attention and Social Competence in Deaf Children with Cochlear Implants. Journal of Developmental and Physical Disabilities, 22(5), 509-532. 
SVIRSKY, M. A., ROBBINS, A. M., KIRK, K. I., PISONI, D. B., \& MIYAMOTO, R. T. (2000). Language Development in Profoundly Deaf Children with Cochlear Implants. Psychological Science, 11(2), 153-158. TOMBLIN, J. B., SPENCER, L., FLOCK, S., TYLER, R., GANTZ, B. (1999). A Comparison of Language in Children with Cochlear Implants and Children Using Hearing Aids. Journal of Speech, Language, and Hearing Research, 42(2), 497-511.

VANDELL, D. L., \& GEORGE, L. B. (1981). Social Interaction in Hearing and Deaf Preschoolers: Successes and Failures in Initiations. Child Development, 52(2), 627-635.

WALTZMAN, S. B. (2006). Cochlear Implants: Current Status. Expert Review of Medical Devices, 3(5), 647-655.

WAUTERS, L. N., \& KNOORS, H. (2007). Social Integration of Deaf Children in Inclusive Settings. Journal of Deaf Studies and Deaf Education, 13(1), 21-36.

WEISEL, A., \& KAMARA, A. (2005). Attachment and Individuation of Deaf/Hard of Hearing and Hearing Young Adults. Journal of Deaf Studies and Deaf Education, 10(1), 51-62.

WEISEL, A., MOST, T., EFRON, C. (2005). Initiations of Social Interactions by Young Hearing Impaired Preschoolers. Journal of Deaf Studies and Deaf Education. 10(2), 161-170

ZWOLAN, T. A., ASHBAUGH, C., ALARFAJ, A., KILENY, P., ARTS, H., ELKASHLAN, H. (2004). Pediatric Cochlear Implant Patient Performance as a Function of Age at Implantation. Otology and Neurotology, 25(2), 112-120.

\section{Contact}

Xie Yuhan,

doctoral student,

Institute of Special Education, Faculty of Education,

Palacký University, Olomouc, Czech Republic.

Faculty of Education Science, Sichuan Normal University

NO. 1819, Chenglong Avenue Longquanyi District

Chengdu city 610101, Sichuan province, P. R. China

e-mail: yuhanxie2007@163.com 